\title{
ANTROPOLOGIA DO DIREITO
}

\section{ANTHROPOLOGY OF LAW}

ANTROPOLOGÍA DEL DERECHO

Rebecca Lemos Igreja

\section{Maria Teresa Sierra Camacho}

Doutora em Sociologia

Centro de Investigaciones y Estudios Superiores en Antropología Social

México

Talita Rampin

Doutora em Direito

Universidade de Brasília

Brasil

\section{Fernando Antônio de Carvalho Dantas}

Doutor em Direito

Universidade Federal de GoiáS

Brasil

\section{Resumo}

Editorial do segundo número, quarto volume, da revista "Abya Yala -Revista sobre acesso à justiça e direitos nas Américas".

Palavras-chave: Acesso à justiça, direito, Américas.

\section{Resumen}

Editorial del segundo número del cuarto volumen, de la revista "Abya Yala -Revista sobre acceso a la justicia y derechos en las Américas".

Palabras clave: Acceso a la justicia, derecho, América.

\section{Abstract}

Editorial of the second issue of the fourth volume, of the magazine "Abya Yala -Journal on access to justice and rights in the Americas".

Keywords: Access to justice, law, Americas. 


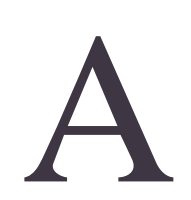

bya-Yala: revista sobre acesso à justiça e direitos nas Américas, publiciza a segunda edição de 2020, pelo qual divulga o dossiê organizado pelas professoras doutoras Ana Lúcia Pastore Schritzmeyer e Bruna Angotti, com trabalhos do VI ENADIR - Encontro Nacional de Antropologia do Direito, realizado entre os dias 26 e 29 de agosto de 2019, na Faculdade de Filosofia, Letras e Ciências Humanas da Universidade de São Paulo.

Agradecemos a colaboração das autoras e autores dos nove artigos e quatro resenhas que integram essa edição: Ana Clara Klink de Melo, Renata Albuquerque de Moraes, Túlio Boso Fernandes dos Santos, Larissa Soares de Melo, Murilo Gaspardo, Luana Barbosa da Silva, Marina de Oliveira Ribeiro, Paulo Victor Leite Lopes, Aline Lopes Murillo, Carla Villalta, Amanda Lacerda Jorge, André Brandão, Perla Alves Bento de Oliveira Costa, Érika Guimarães Ferreira, Andressa Marques Siqueira, Filipe Novaes Pinto, Caroline Laya de Menezes, Pedro Roney Dias Ribeiro, Gabriela Perissinotto de Almeida, Sara Vieira Antunes.

E, em especial, agradecemos às professoras Ana Lúcia Pastore
Schritzmeyer e Bruna Angotti. O trabalho por elas realizado no âmbito do NADIR Núcleo de Antropologia do Direito, assim como nesse dossiê, tem sido essencial no campo da Antropologia e do Direito, fomentando estudos, reflexões críticas sobre questões atuais que emergem de nossa realidade e, principalmente, fortalecendo a formação de uma nova geração de pesquisadoras e pesquisadores.

Desejamos a todas e todos uma excelente leitura!

$$
\begin{gathered}
\text { Rebecca Lemos Igreja } \\
\text { Maria Teresa Sierra Camacho } \\
\text { Talita Rampin }
\end{gathered}
$$

Fernando Antônio de Carvalho Dantas 